\title{
Design of Fracture Fixation Plate for Necessary and Sufficient Bone Stress Shielding*
}

\author{
Kotlanka RAMAKRISHNA**, Idapalapati SRIDHAR ${ }^{* *}$, Sathiamoorthy SIVASHANKER ${ }^{* *}$, \\ Kok Sun $\mathrm{KHONG}^{* * *}$ and Dhanjoo N. GHISTA**
}

\begin{abstract}
The objective of treating the fractured bone is to achieve painless functioning of the bone and undisturbed healing at the fracture. Internal fixation by stiff bone-plate is one of the standard methods to achieve these objectives. Recently, there is considerable interest in the usage of compliant plates to enhance bone healing with reduced stress shielding. Herein, first an analytical solution is developed to determine screw forces in the bone-plate assembly that conforms the plate and the bone under bending load. Based on the analytical calculations, an optimal fixator plate selection criterion for necessary and sufficient stress shielding is proposed. Second, effectiveness of employing a non-homogeneous stiffness graded (SG) plate rather than a homogeneous stainless steel (SS) plate for stress shielding is investigated using a finite element method. It is found that stress shielding on bone by SG plate is less compared to SS plate.
\end{abstract}

Key Words: Bone, Bending Moment, Stress Shielding, Stiffness Graded Materials, Finite Element Analysis

\section{Introduction}

Bone is the main constituent of the skeletal system and it differs from the connective tissue primarily due to its rigidity and strength. A strong and stiff bone enables the skeleton to maintain body shape, to protect the internal organs, to provide a frame for the bone marrow, and to transmit force of the muscular contraction from one part of the body to another during movement ${ }^{(1)}$. Fatigue and impact loads are the most common reasons for bone fracture. Fractured bones need to be fixed surgically for it's healing and proper functioning as early as possible. Different techniques are used in the clinical treatment of long bone fractures. Most of the simple fractured long bones are treated by conservative non-operative methods of external immobilization. Another method to treat fractures is by intramedullary rod fixation. Muller et al. ${ }^{(2)}$ have advocated open reduction and internal fixation using boneplate and screws. Fracture-fixation by bone-plate provides rigid immobilization at the fracture site and reduces the

* Received 27th May, 2004 (No. 04-5083)

** School of Mechanical \& Production Engineering, Nanyang Technological University, 50 Nanyang Avenue, 639798, Singapore. E-mail: mdnghista@ntu.edu.sg

*** Mt. Elizabeth Medical Center, 3 Mt. Elizabeth, 228510, Singapore fracture gap thus allowing primary bone healing by endosteal callus formation. In general, early union was observed and can be applied to most of the fractures (simple and compound), including the fractures on irregular bones. The role of bone-plate and screws is to hold the fragments of the bone in position till the bone heals. Some of the complications associated with internal plate fixation are loosening of screws, local effects on vascularity of the cortex beneath the plate (blocking the normal blood flow) and excessive shielding of stresses from bone. The factors governing the success of healing in a fracture treated by internal fixation $^{* 1}$ (using plate and screws) are: (1) the apposition, or degree of contact or separation, of the broken bone fragments from each other, (2) alignment of fragments, (3) the fixation or prevention of further movement of the fragments i.e. absolute stability, and (4) other individual features, such as age, health, and nutritional status of the person involved ${ }^{(2)}$.

In the internal fixation, absolute stability of fixation can be achieved by applying interfragmentary compression between the fracture ends of the bone. Interfragmentary compression prevents relative movement of the fractured ends of bone by generating frictional resis-

*1 The term 'internal fixation' in this paper refers to fracture fixation by bone-plate and screws. 
tance. Compression at the fracture enables the primary bone healing and the bone-plates must remain in place for about 2 years (as a rule) $)^{(3)}$. In internal fixation, compressive strains are generated at the fracture site by using pretensioning/pre-bending of the plate before fixation, Dynamic Compression Plate (DCP), or applying lag screw across the fracture site ${ }^{(4)}$. However, the results can range from successful healing to no healing ${ }^{(5)}$. In all situations, healing is slowed or stopped if the individual is in poor health, poor nutritional condition, or poor medical support/attention.

The idea of internal fixation has branched off into two directions. The first relates to the application of conventional high stiffness plates (essentially made of $316 \mathrm{~L}$ Stainless Steel) and with interfragmentary compression, the second concerns the flexible (stiffness of the plate almost equal to that of bone) plates made of composite material $^{(6)-(8)}$. LCP (locking compression plate) is the latest bone-plate design where there is no direct contact between plate and the bone ${ }^{(9)}$. However, the long-term effect of using the bone-plate is that the bone remodels itself due to the changed stress-conditions induced by the bone-plate ${ }^{(10),(11)}$. Remodeling of bone will result in the loss of density and surface resorption in case of the boneplate fixation. The relationship between implant stiffness and the extent of bone loss does suggest that the change in bone morphology is an effect of stress shielding and subsequent adaptive remodeling processes. Factors influencing stress shielding are bone-plate design (geometry and material), interface-bonding characteristics, physiological stresses and bone adaptation. The bone-plate design should be improved to provide about $2.0 \%$ compressive strain at fracture interface at the initial stages of healing and minimize stress shielding after complete healing $^{(17)}$. Also, the bone-plate should withstand the in-vivo loading demands that in turn will provide an early painfree mobilization of muscles and joints adjacent to the fracture $^{(12)}$. Usually the experience and the skill of the surgeon guides in selecting a plate with appropriate stiffness and geometry. A numerical or analytical model should be of much use to guide the surgeon for selecting the correct combination of stiffness and thickness of the bone-plate.

Axial compressive load is more prominent in the long bones and it is not hazardous as more interfragmentary compression at fracture site is achieved. However, due to the eccentric load from the center of the bone-plate and the curvature in the long bone, bending moment is applied to the fracture fixed bone. Bending moment will induce both tensile and compressive stresses across the fracture site, and open up the fracture leading to the reduction in the stability of the fixation. From an engineering perspective, fractured fixed bone assembly is the weakest in bending $^{(13)}$.

In this paper, first using composite beam theory of strength of materials an analytical model is developed to calculate the forces in the screws used to fix a fractured bone by a plate. Based on the forces in the screws, force in the plate, and the bone, an optimal selection criterion of bone-plate is offered for necessary and sufficient stress shielding. Second, employing a finite element method, use of stiffness graded bone plate as a potential substitute to the homogeneous stainless steel bone plate is explored by investigating the extent of stress shielding.

\section{Symbols}

$E_{p}$ : Modulus of plate

$E_{b}$ : Modulus of bone

$E_{c}$ : Modulus of callus

$d_{b}$ : Diameter of bone

$t$ : Thickness of plate

$l=x / 2:$ Length of the plate

$A_{p}:$ Cross-sectional area of plate

$A_{b}$ : Cross-sectional area of bone

$M$ : Bending Moment

$\sigma:$ Normal stress

$I_{p} \& I_{b}:$ Moment of inertia of plate and bone

$y_{1}$ : Distance between NA and center of plate

$y_{2}$ : Distance between NA and center of bone

$a$ : Distance between the screws

$\mathrm{G}$ : Shear modulus

$v$ : Poisson's ratio

\section{Plate Reinforced Bone (PRB) Model and Analysis}

The bone-plates immediately after fracture fixation shield the bone from tensile stresses at the fracture interface (site 1) and away from the fracture interface (site 2) as shown in Fig. 1. While the tensile stress shielding at site 1 is necessary to promote healing, that at site 2 they can cause osteoporosis ${ }^{(14)}$. This problem may be resolved by satisfying two objectives: (i) designing for the neutral axis (NA) at site 1 to be at the plate-bone interface to ensure that no tensile stresses are transferred to the callus while it is being formed, and (ii) designing for the NA at site 2 to be as far into bone as possible so that the bone is subjected to the normally prevalent tensile stresses. These two requirements can be satisfied by careful tailor-made design of the plate modulus and geometry.

When a beam is subjected to hogging bending moment (as shown in Fig. 2), the material above the neutral

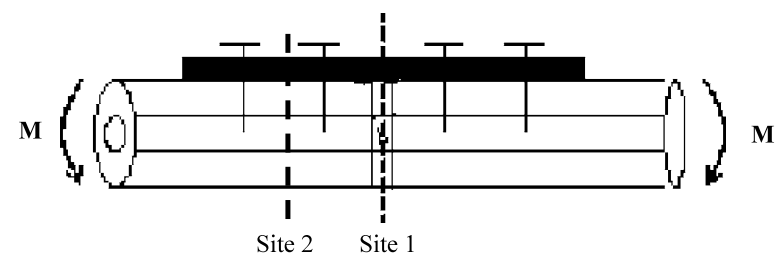

Fig. 1 Plate Reinforced Bone (PRB) system under pure bending 


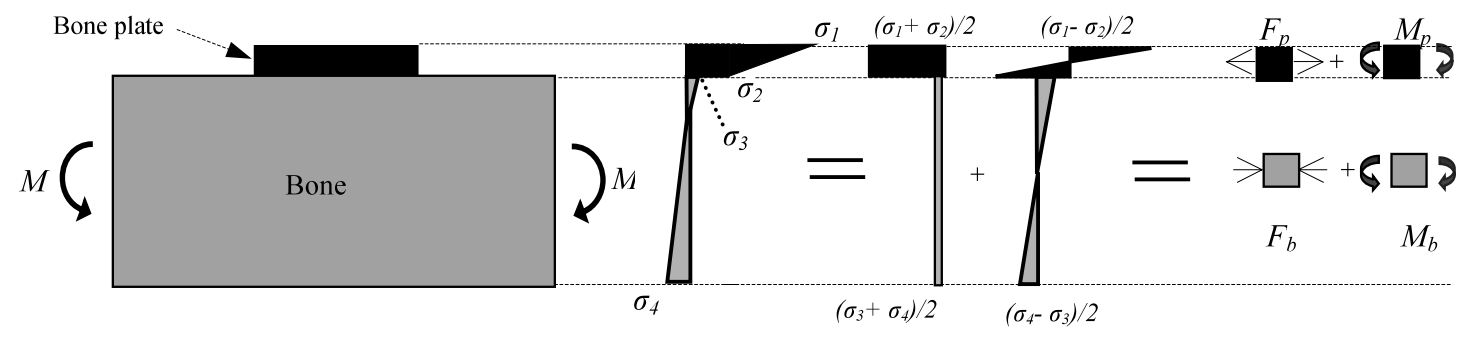

(a)

(b)

(c)

Fig. 2 Normal stress distribution for bone-plate assembly under bending moment

axis is subjected to tensile stresses and the material below the neutral axis bears compressive stresses. For a fractured bone, the bone-plate is fixed to on the tension side of the bone ${ }^{(15)}$. The compatibility criterion for the bending analysis is that the curvature or bending strain should be same in the bone-plate and bone along the contact (bone and plate) interface. In order to identify the role of the screws under bending, the total moment taken up by the plate and the shear force on the screws needs to be calculated.

A typical plate reinforced bone (PRB), subjected to a bending moment, $M$, is illustrated in Fig. 1 . Both the bone and bone-plate in internal fixation are assumed to behave as a composite beam after healing: the plate is assumed to be perfectly bonded to the bone. Normal stress distribution for moment $(M)$ is shown in Fig. 2, where $\sigma_{1}, \sigma_{2}$, $\sigma_{3}$ and $\sigma_{4}$ are the stresses at top surface of plate, bottom surface of plate, top surface of bone and bottom surface of bone respectively. As shown in Fig. 2 (c), the stress in plate is due to an axial tensile force, $F_{p}$ and a bending moment, $M_{p}$. Similarly, the stress in bone is due to an axial compressive force, $F_{b}$, and a moment, $M_{b}$.

Stress state can be given by: $\sigma_{1}=\frac{M E_{p} C}{S} ; \sigma_{2}=$ $\frac{M E_{p}(C-t)}{S} ; \sigma_{3}=\frac{M E_{b}(C-t)}{S} ; \sigma_{4}=-\frac{M E_{b}\left(d_{b}+t-C\right)}{S} ;$ where $I_{p}^{\prime}=I_{p}+A_{p} y_{1}^{2}, I_{b}^{\prime}=I_{b}+A_{b} y_{2}^{2}, C$ is the distance between neutral axis and the top surface of the plate and $S=E_{p} I_{p}^{\prime}+E_{b} I_{b}^{\prime}$.

The moments and the axial forces that are shared by plate and bone are given by:

$$
\begin{aligned}
M_{p} & =\frac{M I_{p}^{\prime} E_{p}}{S} ; \quad M_{b}=\frac{M I_{b}^{\prime} E_{b}}{S} ; \\
F_{p} & =\frac{M E_{p}(2 C-t)(b t)}{2 S} ; \\
F_{b} & =\frac{\pi\left(M E_{b}\right)\left(2 C-2 t-d_{b}\right) d_{b}^{2}}{8 S} .
\end{aligned}
$$

Now we relax the perfect bond assumption between the bone and the fixator plate, and they are assumed to be held together by means of four screws: two on either side from the mid span. Further we assume that the two extreme screws rigidly fix the bone and plate assembly and are subjected to the axial forces and moments as detailed above.

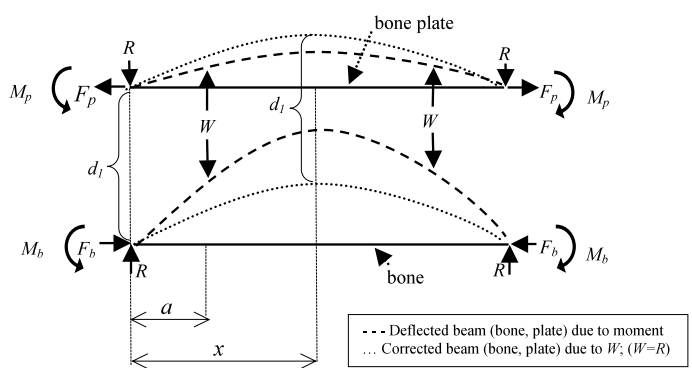

Fig. 3 Free body diagram of bone and plate as a composite beam with clamped boundary condition

With moments $M_{p}$ and $M_{b}$, the deflections in plate and bone will be different. Under this loading, compliant bone deflects more than the plate. In order for the bone and plate to deflect by the same amount, forces have to be applied through screws. Let the forces through screws be represented as ' $W$ ', which are equal in magnitude and opposite in direction and conform the plate and the bone to have the same amount of deflection. The free body diagram of plate and bone are shown in Fig. 3. In other words, ' $W$ ' is the force acting on plate through the screw to increase the plate deflection. Similarly, $W$ is the force imposed on the bone by the screw to restrict its deflection. Thus, upon making deflections of plate and bone at the mid span equal $(x>a>0)$, we obtain

$$
\begin{aligned}
& \frac{1}{E_{p} I_{p}} \int_{0}^{x} \int_{0}^{x}\left\{\left[M_{p}-W(x-a)+W x\right] d x\right\} d x \\
& =\frac{1}{E_{b} I_{b}} \int_{0}^{x} \int_{0}^{x}\left\{\left[M_{b}+W(x-a)-W x\right] d x\right\} d x
\end{aligned}
$$

wherein ' $x$ ' is half the length of plate.

The constants of integration become zero with the clamped boundary conditions i.e. deflection and slope are zero at $x=0$. Hence, Eq. (1) can be rewritten as

$$
W=\frac{\left[M_{b}(\bar{E} \bar{I})\right]-M_{p}}{a(1+\bar{E} \bar{I})}
$$

where $\bar{E}$ is the ratio between modulus of plate and modulus of bone, while $\bar{I}$ is the ratio between moment of inertia of plate and moment of inertia of bone.

The variation of normalized load $(W a / M)$ with $\bar{E}$ as a function of $\bar{I}$ is shown in Fig. 4 and the conclusions that 


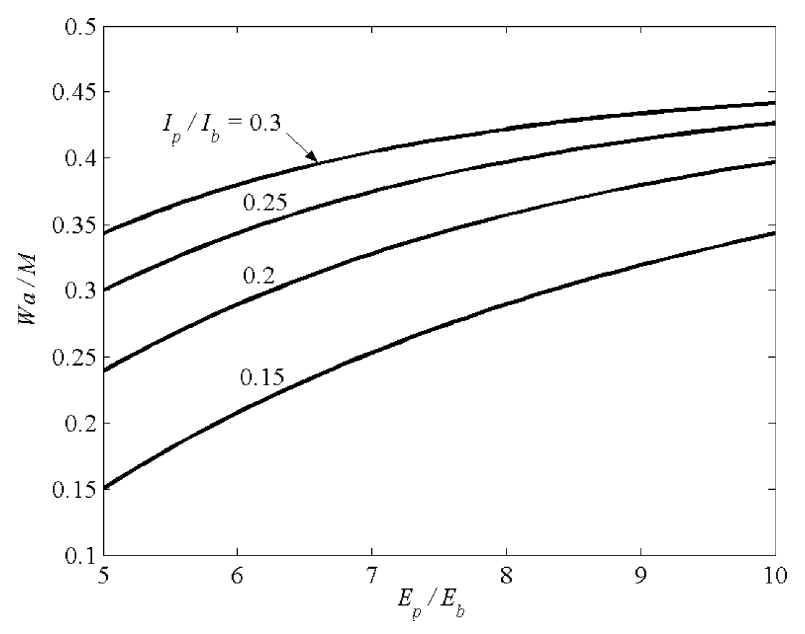

Fig. 4 Variation of normalized screw force with $\bar{E}$ for various values of $\bar{I}$

can be drawn from this figure are (i) for the practical values of $\bar{E}$, the normalized shear load in the screws increases monotonically with $\bar{I}$, (ii) for a specific plate modulus $\left(E_{p}\right)$ $W$ increases with plate thickness, (iii) for a specific plate thickness screw force ' $W$ ' increases with plate Young's modulus $E_{p}$ and (iv) ' $W$ ' decreases by increasing the distance $(a)$ between the screws. It was shown that for a boneplate assembly under uniaxial tensile/compressive load the load transferred by the screws is independent of their separation distance $^{(22)}$.

As a case study, let us assume the modulus of callus $\left(E_{c}\right)$ in the initial stages of healing as $1 \mathrm{GPa}$. The force in the screw ' $W$ ' can be calculated from Eq. (3) as

$$
\begin{aligned}
& \frac{1}{E_{p} I_{p}} \int_{0}^{x} \int_{0}^{x}\left\{\left[M_{p}-W(x-a)+W x\right] d x\right\} d x \\
& =\int_{0}^{x-k} \int_{0}^{x-k} \frac{1}{E_{b} I_{b}}\left\{\left[M_{b}+W(x-a)-W x\right] d x\right\} d x \\
& +\int_{x-k}^{x} \int_{x-k}^{x} \frac{1}{E_{c} I_{c}}\left\{\left[M_{b}+W(x-a)-W x\right] d x\right\} d x
\end{aligned}
$$

where $k$ is half the thickness of the crack.

The free body diagram of the PRB, in Fig. 5 illustrates the applied bending moment, $M_{b}$, axial compressive force $F_{b}$, internal screw forces, $W$ on bone and the variation of the bending moment on the bone. The following equations provide the normal stress distribution across the bone cross-section at sites 1 and 2, due to the applied moment $M$ :

( i ) Tensile stress at the top surface of bone at site 1: $\left(\frac{\left(M_{b}-W a\right) d_{b}}{2 I_{b}}-\frac{F_{b}}{A_{b}}\right)$

(ii ) Compressive stress at the bottom surface of the bone at site $1:\left(-\frac{\left(M_{b}-W a\right) d_{b}}{2 I_{b}}-\frac{F_{b}}{A_{b}}\right)$

(iii) Tensile stress at top surface of plate at site 2 :

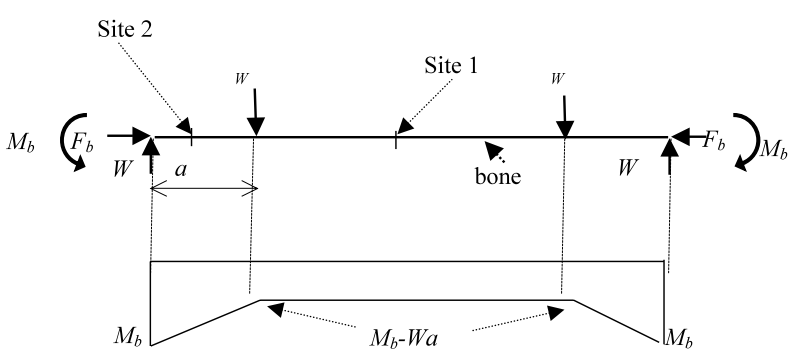

Fig. 5 Bending moment diagram on bone

\begin{tabular}{|c|c|c|c|c|c|c|}
\hline \multicolumn{2}{|c|}{\begin{tabular}{|l} 
Modulus \\
of callus \\
$(\mathrm{GPa})$
\end{tabular}} & $\begin{array}{l}\text { Modulus } \\
\text { of plate } \\
(\mathrm{GPa})\end{array}$ & $\begin{array}{l}\begin{array}{l}\text { Thickness } \\
\text { of plate } \\
\text { (mm) }\end{array} \\
\text { (mm }\end{array}$ & $\begin{array}{l}\text { Bending } \\
\text { stiffness, } \\
\text { EI }\left(10^{5}\right. \\
\left.\mathrm{Nmm}^{2}\right)\end{array}$ & $\begin{array}{l}\text { Stress at } \\
\text { fracture site } \\
\text { underneath the } \\
\text { plate }\left(\mathrm{N} / \mathrm{mm}^{2}\right)\end{array}$ & $\begin{array}{l}\text { Stress away from } \\
\text { second screw and } \\
\text { underneath the } \\
\text { plate }\left(\mathrm{N} / \mathrm{mm}^{2}\right)\end{array}$ \\
\hline \begin{tabular}{|l|} 
Case \\
1
\end{tabular} & \begin{tabular}{|l|l}
1 \\
\end{tabular} & \begin{tabular}{|l|}
210 \\
$(316 \mathrm{~L}$ \\
Stainless \\
steel)
\end{tabular} & $\begin{array}{l}2 \\
3 \\
4 \\
5\end{array}$ & \begin{tabular}{r|}
21.0 \\
70.9 \\
168.0 \\
328.1 \\
\end{tabular} & $\begin{array}{r}0.6780 \\
\mathbf{- 0 . 0 3 0 1} \\
-0.1199 \\
-0.1051 \\
\end{array}$ & $\begin{array}{l}3.110 \\
\mathbf{2 . 0 0 4} \\
1.250 \\
0.825\end{array}$ \\
\hline $\begin{array}{l}\text { Case } \\
2\end{array}$ & 1 & $\begin{array}{l}110 \\
\text { (Titanium } \\
\text { alloy: Ti- } \\
6 \mathrm{Al}-4 \mathrm{~V} \text { ) } \\
\end{array}$ & $\begin{array}{l}2 \\
3 \\
4 \\
5 \\
\end{array}$ & \begin{tabular}{r|}
11.0 \\
37.1 \\
$\mathbf{8 8 . 0}$ \\
171.8 \\
\end{tabular} & $\begin{array}{r}1.4320 \\
0.2351 \\
\mathbf{- 0 . 0 8 1 8} \\
-0.1327 \\
\end{array}$ & $\begin{array}{l}3.500 \\
2.695 \\
\mathbf{1 . 9 0 0} \\
1.346 \\
\end{array}$ \\
\hline \begin{tabular}{|l} 
Case \\
3 \\
\end{tabular} & 1 & \begin{tabular}{|l|}
50 \\
(Carbon \\
fibre \\
reinforced \\
polymer)
\end{tabular} & $\begin{array}{l}2 \\
3 \\
4 \\
5\end{array}$ & $\begin{array}{r}5.0 \\
16.8 \\
40.0 \\
78.1\end{array}$ & $\begin{array}{l}2.4900 \\
0.9400 \\
0.1974 \\
0.0666\end{array}$ & $\begin{array}{l}3.827 \\
3.352 \\
2.732 \\
2.156\end{array}$ \\
\hline
\end{tabular}

Table 1 Design parameters of bone plate and calculated stress values at site 1 and 2

$\left(\frac{\left(M_{b}\right) d_{b}}{2 I_{b}}-\frac{F_{b}}{A_{b}}\right)$ and

(iv) Compressive stress at the bottom surface of the bone at site $2:\left(-\frac{\left(M_{b}\right) d_{b}}{2 I_{b}}-\frac{F_{b}}{A_{b}}\right)$

As an example, consider the design parameters of bone diameter $15 \mathrm{~mm}$, plate of $15 \mathrm{~mm}$ width and $60 \mathrm{~mm}$ length, distance between the screws $20 \mathrm{~mm}$ and a bending moment of $1 \mathrm{Nm}$ on the bone-plate assembly. This bending moment produces a shear force of $35 \mathrm{~N}$ in the screw. The stresses in bone at fracture site and away from it are tabulated in Table 1.

From Table 1, it is noticed that in case 1, to have NA inside the plate at site 1 , and maximum tensile stress in the top layer of the bone at site 2, the thickness of the plate should be at least $3 \mathrm{~mm}$. Similarly in case 2, the plate thickness should be $4 \mathrm{~mm}$. However, for the modulus of plate to be less than $50 \mathrm{GPa}$ (case 3), the NA is shifted into the bone and thus causes some tensile stress in the upper layer of bone (i.e. at site 1) leading to delayed healing. Hence, the optimal plate should have: modulus of plate $=210 \mathrm{GPa}$ and thickness $=3$ or $4 \mathrm{~mm}$ for the cases considered. The analysis can be extended further for fixation by 3 and 4 screws also ${ }^{(23)}$.

\section{Stiffness Graded Bone Plates for Fracture Fixa- tion: A Finite Element Study}

The recommendations in the previous section are to support primary bone healing with absolute stability at the fracture site. Recently, treatment of fracture fixation by plates of compliant materials has emerged. The 
aim of using compliant plates is to take the support of biological tissue response at the fracture ${ }^{(3),(16)}$. Flexible/compliant plates will not provide absolute stability (as in case 3 where the callus is subjected to tensile stress) at the fracture interface and there is a certain amount of interfragmentary movement (movement which provides $2 \%$ strain), which initiates callus formation. Also flexible bone-plate offers less stress shielding. Too much of interfragmentary movement ( $>2 \%$ gap strain) will lead to the formation of cartilage or extra cellular matrix ${ }^{(17)}$. Thus suitable stiffness plate is to be designed such that it improves healing and avoids stress shielding.

Herein, we want to demonstrate the capacity of stiffness-graded plates (SG Plate) to alleviate stress shielding of the bone, while simultaneously enabling adequate callus-building (and bone-forming) compressive stress at the fracture interface. Hence, in order to compare the stress-states obtained for stainless steel (SS) and SG plates a three-dimensional finite element analysis (FEA) is carried out on the bone-plate assemblies (with screws) under bending load.

Commercial FE code ABAQUS/Standard is used to carry out the stress analysis on a fracture fixed bone by bone-plate and six screws under four-point bending load. The bone is modeled as a circular tube with an external diameter $24 \mathrm{~mm}$ and an internal diameter $12 \mathrm{~mm}$, while the bone-plate is modeled so as to conform to the bone shape (plate length $100 \mathrm{~mm}$, thickness $5 \mathrm{~mm}$ and width $12 \mathrm{~mm}$ ) with six tapered holes at equal spacing for the purpose of fixing it on to bone. The main function of screw thread is to prevent the screw from being moved along its axial direction. To model this function and to limit the number of elements in the analysis, only two threads were incorporated onto the screw design ${ }^{(18),(19)}$. The two threads (major diameter $3.5 \mathrm{~mm}$ and minor diameter $2.5 \mathrm{~mm}$ and length $30 \mathrm{~mm}$ ) located in such a way that one thread is in the upper material portion of the bone and the other is in the lower material portion of the bone. The screw head matches the tapered hole of the bone plate. Three-dimensional part geometries of bone, bone-plate and screws were drawn using the Pro/Engineer geometrical modeling package (version 2001). These 3D geometries were imported from Pro/Engineer to ABAQUS with the help of CAD translator "STEP". Bone, plate and the screws are assembled to simulate Least Contact-Dynamic Compression Plate (LC-DCP). In the assembly as shown in Fig. 6, bone and the plate are separated by a gap of $0.5 \mathrm{~mm}$. The geometry of the threaded holes in the bone and taper hole in the plate mate (confirm) with the screw dimensions.

The screw is assumed to be made of titanium alloy Ti-6Al-4V with Young's modulus of $105 \mathrm{GPa}$ and Poisson's ratio of 0.3 . The 316L stainless steel bone-plate has a Young's modulus of $200 \mathrm{GPa}$ and Poisson's ratio

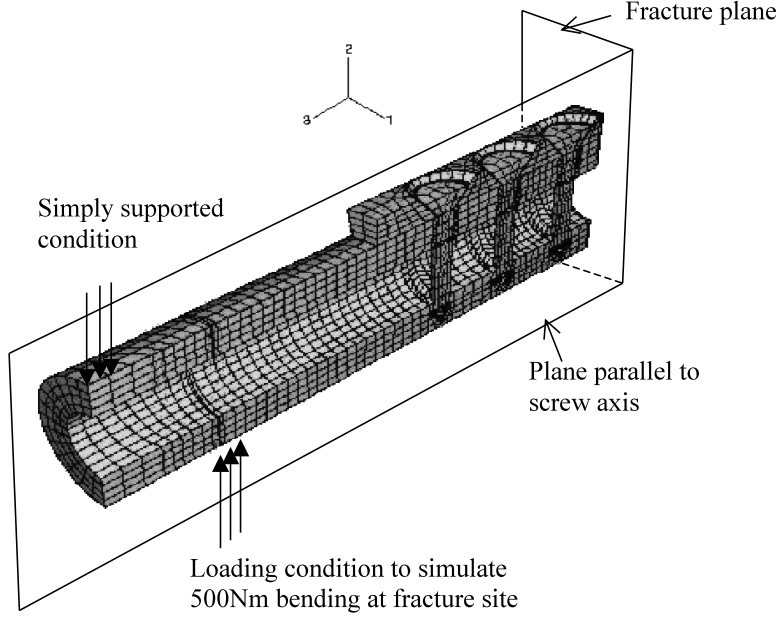

Fig. 6 Finite element mesh of the bone, plate and screw. Applied boundary and four-point bending load conditions are shown. Bone diameter is $24 \mathrm{~mm}$, plate thickness $5 \mathrm{~mm}$.

of 0.3. The bone is considered as orthotropic material and the material properties assigned are $E_{1}=14.5 \mathrm{GPa}$, $E_{2}=14.5 \mathrm{GPa}, E_{3}=19.7 \mathrm{GPa}, G_{12}=7.0 \mathrm{GPa}, G_{13}=$ $7.0 \mathrm{GPa}, G_{23}=5.28 \mathrm{GPa}, v_{12}=0.285, v_{13}=0.285$, and $v_{23}=0.265^{(20),(21)}$ (see Fig. 6 for axis convention). For SG Plate, the Young's modulus value at the center of plate is $200 \mathrm{GPa}$ (at fracture site) and decreases linearly towards the ends of the plate to $20 \mathrm{GPa}$ and a constant Poisson's ratio of 0.3 is assumed throughout the length. The constitutive behavior of bone, plate and screws are that of a linear elastic material governed by Hooke's law.

When the assembly (bone, plate and screw assembly) is subjected to a bending moment, the bone, plate and screw will compress each other. Appropriate contact interfaces between the plate and the bone, between the screw and the bone, between the screw and the plate have been created. In order to model the interactions of these contacts, contact elements (surface to surface contact) available in ABAQUS are used with coefficient of friction $(\mu)$ as 0.9 between the bone and screw contacts and 0.37 is used between the plate and bone contact surfaces ${ }^{(11)}$.

In order to simulate the self-locking screw mechanism (in LC-DCP) between the plate and screw, the screw is fixed to the plate by tieing the nodes at the contact surfaces between plate and screw. Symmetry with reference to the loading and geometry is used to reduce the computational effort: The model is symmetric about the fracture plane and also about the long axis of the bone in a plane parallel to the screw axis (see Fig. 6). A finer mesh is chosen for the surfaces-contact sites. Bending moment of $500 \mathrm{Nm}$ is applied through four point bending. In general, $150-200 \mathrm{Nm}$ bending moment is applied on the bone (essentially tibia) in normal gait and will reach to a maximum of 500-600 Nm while running or accidental loads that will cause failure of the fracture fixation ${ }^{(1),(2),(12),(13)}$. 


\subsection{Results and discussion}

The Von-Mises stress contours (effective stress) within the bone and plate are shown in Figs. 7 (a) to 7 (d) and 8 (a) to 8 (d). The stresses in the plate are maximum in the screw hole located close to the fracture site, and its value is noted to be $609 \mathrm{MPa}$ for SG plate and $582 \mathrm{MPa}$ for stainless steel plate. This raises the need to improve the plate design such that plate will not fail at screw hole near to the fracture. Maximum stresses in the bone are noticed at the screw holes due to the concentrated contact stresses. Higher stresses at the bone cavities will initiate bone remodeling process and bone density surrounding the screw will increase which in turn will contribute to the better holding of the screws. However, the screw becomes loose (a)

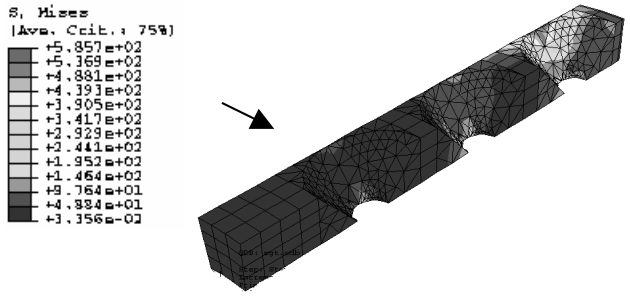

(b)

ร, 822

(b)

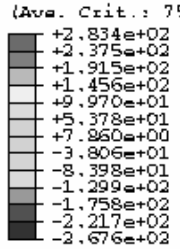

(c)

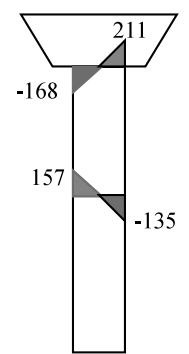

Farthest screw from fracture<smiles>[2H]C(C)C</smiles>

(d)

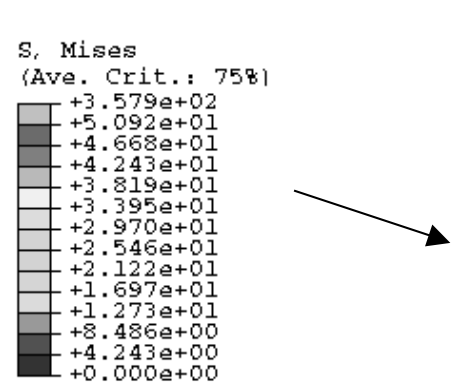

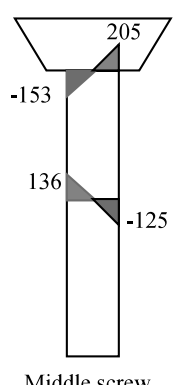

Middle screw

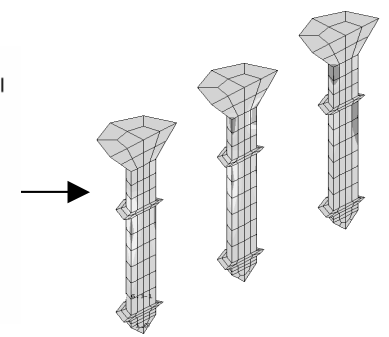

Nearest screw to the fracture

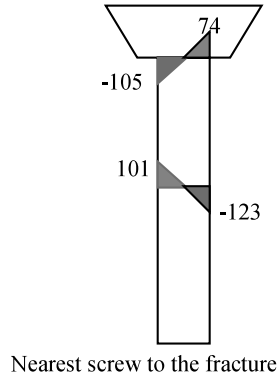

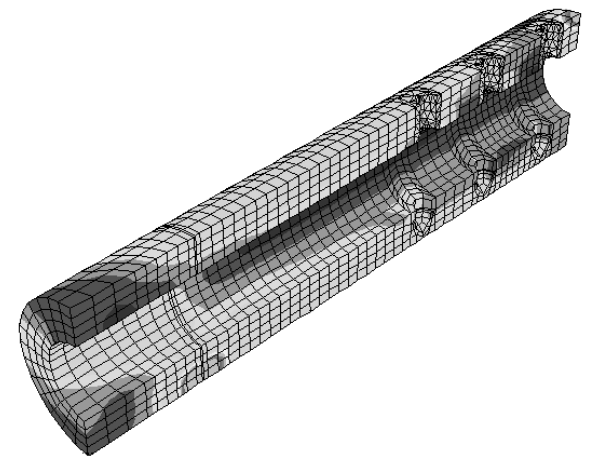

S, 533

(Ave, Crit, ; 758 )

(e)

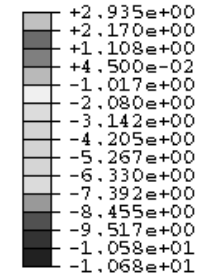

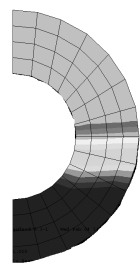

Cross-section at farthest screw from fracture

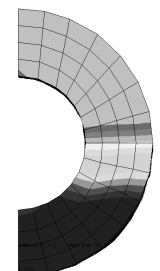

Cross-section at middle screw

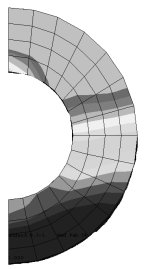

Cross-section at nearest screw to the fracture

Fig. 7 Analysis of fixation with Stainless-steel plate (a) Von-Mises stresses (MPa) in the plate (b) Stresses in screws (MPa) along the axis of the screws (c) Normal stress (MPa) developed in the screws while loading (d) Von-Mises stresses (Mpa) in the bone (e) Stress distribution (MPa) in bone at various cross-sections 
(a)

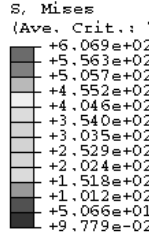

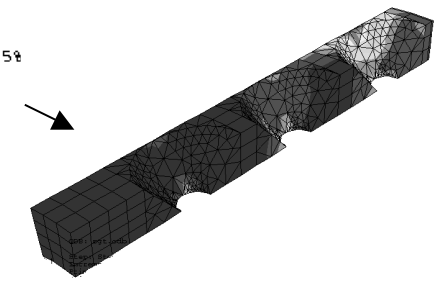

(b) $\mathrm{s}, \mathrm{s} 22$
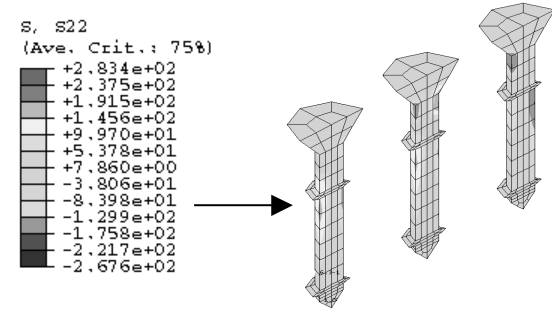

(c)

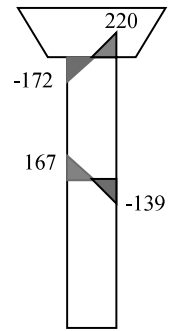

Farthest screw from fracture

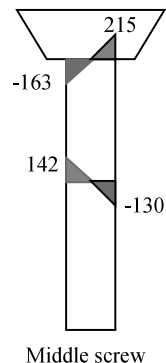

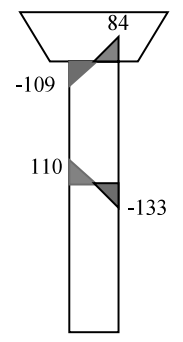

Nearest screw to the fracture

(d)
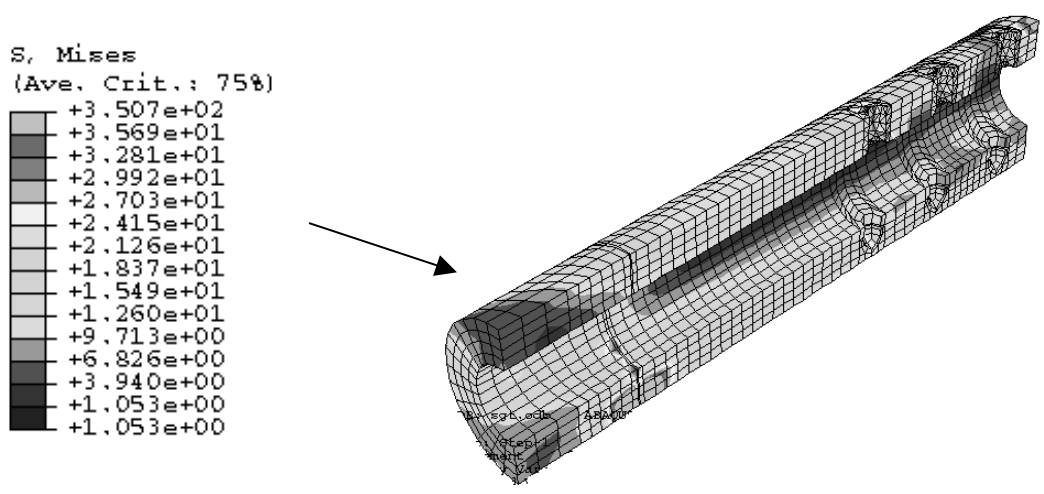

(e)
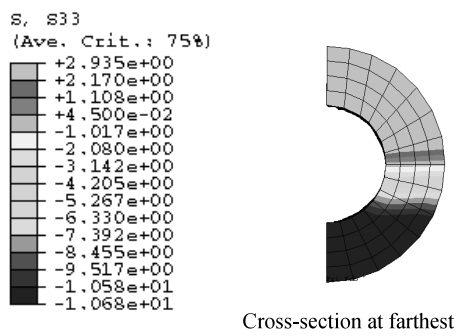
screw from fracture
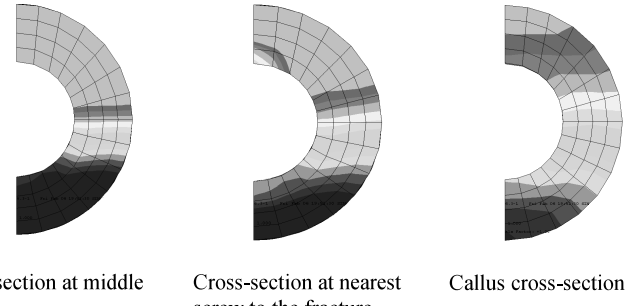

Cross-section at neares

Callus cross-section

Fig. 8 Analysis of fixation with Stiffness-graded plate (a) Von-Mises stresses (MPa) in the plate (b) Stresses in screws (MPa) along the axis of the screws (c) Normal stress (MPa) developed in the screws while loading (d) Von-Mises stresses (MPa) in the bone (e) Stress distribution (MPa) in bone at various cross-sections

in the initial stages of healing due to its micro-motion under normal loading.

The tensile load on the screws $(11.2 \mathrm{~N}$ for outer most screw from fracture and $7.9 \mathrm{~N}$ for nearest screw from fracture for SS plate; $13.0 \mathrm{~N}$ for outer most screw from fracture and $7.9 \mathrm{~N}$ for nearest screw from fracture for $\mathrm{SG}$ plate) in bending load is lower than the pull out strength of the screws $(61 \pm 12 \mathrm{~N})^{(18)}$. So the weakest component in the assembly is the plate. The importance of the bending stiffness of the screw is also identified from the analysis. It can be seen from Figs. 7 (c) and 8 (c) that the screws are sub- jected to bending moments with the maximum effective stress in them occurring at the top screw thread. Necessary care should be taken in selecting the suitable screws such that the screws will resist the bending moments generated while loading.

The Table 2 summarizes the main features of SG and SS plate fixations. The SG plate generates relatively higher compressive stresses in the callus zone compared to SS plate, thereby providing better bone-healing potential and offers better stability to the fixation at fracture site. The location of the NA after first screw with SG plate as- 
Table 2 Effectiveness of stiffness graded plate compared with stainless steel plate

\begin{tabular}{|c|c|c|c|c|c|}
\hline $\begin{array}{l}\text { Fixator } \\
\text { plate } \\
\text { material }\end{array}$ & $\begin{array}{l}\text { Computed } \\
\text { values for the } \\
\text { bone }\end{array}$ & $\begin{array}{l}\text { Crack } \\
\text { Interface }\end{array}$ & $\begin{array}{l}\text { In cross-section } \\
\text { at first screw }\end{array}$ & $\begin{array}{l}\text { In cross-section } \\
\text { at second screw }\end{array}$ & $\begin{array}{l}\text { In cross section } \\
\text { at third screw }\end{array}$ \\
\hline \multirow[t]{3}{*}{$\begin{array}{l}\text { Stainless- } \\
\text { steel plate }\end{array}$} & $\begin{array}{c}\text { Maximal } \\
\text { tensile stress } \\
\text { (MPa) }\end{array}$ & 2.6 & 11.00 & 15.00 & 22.3 \\
\hline & $\begin{array}{l}\text { Minimum } \\
\text { compressive } \\
\text { stress (MPa) }\end{array}$ & -10.57 & -16.20 & -20.9 & -21.88 \\
\hline & $\begin{array}{c}\text { Neutral Axis } \\
\text { from top of } \\
\text { the bone } \\
(\mathrm{mm})\end{array}$ & 4.8 & 9.1 & 9.9 & 11.5 \\
\hline \multirow[t]{3}{*}{$\begin{array}{l}\text { Stiffness- } \\
\text { Graded } \\
\text { Plate }\end{array}$} & $\begin{array}{c}\text { Maximal } \\
\text { tensile stress } \\
\text { (MPa) }\end{array}$ & 2.9 & 12.49 & 16.17 & 23.94 \\
\hline & $\begin{array}{c}\text { Minimum } \\
\text { compressive } \\
\text { stress (MPa) }\end{array}$ & -11.5 & $\begin{array}{l}-16.3 \\
\end{array}$ & -21.19 & -25.00 \\
\hline & $\begin{array}{c}\text { Neutral Axis } \\
\text { from top of } \\
\text { the bone } \\
(\mathrm{mm})\end{array}$ & 4.9 & 10.1 & 10.5 & 11.7 \\
\hline
\end{tabular}

sembly is nearer to the bone neutral axis when compared with the NA location with SS plate assembly. Thus, the SG plate reduces the stress shielding of the bone by generating higher stresses in the bone, hence preserves its density and strength.

\section{Conclusions}

An analytical theory for the optimal design of plate fixation for fractured long bones has been developed. The design analysis is such that (i) at the fracture site, the bone is subjected to compressive stresses along its crosssection, (ii) away from the fracture site, top layers of the bone experience maximum tensile stresses, and (iii) the thickness of the plate is as small as possible while its modulus is as high as possible. The proposed methodology is useful in eliminating the stress shielding effects in bone fracture fixation treatment. Secondly, the results from finite element analysis reveal that SG plates enhance bone healing and offer reduced stress shielding than SS plates.

\section{References}

( 1 ) Tencer, A.F. and Johnson, K.D., Biomechanics in Orthopeadic Trauma, Bone Fracture and Fixation, 1st Edition, (1994), Martin Dunitz.

( 2 ) Muller, M.E., Allgower, M., Schneider, R. and Willengger, H., Manual of Internal Fixation, Techniques Recommended by the AO-ASIF Group, 3rd Edition, (1991), Springer-Verlag, New York.

( 3 ) Perren, S.M., Backgrounds of the Technology of Internal Fixators, Injury, Int. J. Care Injured, Vol.34 SB (2003), pp.1-3.

( 4 ) Albright, J.A., Johnson, T.R. and Saha, S., Principles of Internal Fixation, Orthopaedic Mechanics: Procedures and Devices, Edited by Ghista, D.N. and Roaf, R., (1978), pp.123-229, Academic Press.

( 5 ) Mc Kibbin, B., The Biology of Fracture Healing in Long Bones, The Journal of Bone and Joint Surgery, Vol.60B, No.2 (1978), pp.150-162.

( 6 ) Ali, M.S., French, T.A., Hastings, G.W., Rae, T.,
Rushton, N., Ross, E.R.S. and Wynn-Jones, C.H., Carbon Fiber Composite Bone Plates, Journal of Bone and Joint Surgery, Vol.72-B (1990), pp.586-591.

( 7 ) Amnon, F., Alan, J.Y. and Hans, K.U., Improved Fracture Healing with Less Rigid Plates, Clinical Orthopaedics and Related Research, Vol.39, No.3 (1997), pp.232-245.

( 8 ) Fujihara, K., Haung, Z., Ramakrishna, S., Satknanantham, K. and Hamada, H., Performance Study of Braided Carbon/PEEK Composite Compression Bone Plates, Journal of Biomaterials, Vol.24 (2003), pp.2661-2667.

( 9 ) Miclau, T. and Martin, R.E., The Evolution of Modern Plate Osteosynthesis, Injury, Int. J. Care Injured, Vol.28 A3 (1997), pp.3-6.

(10) Tonino, L., Davidson, C.L., Klopper, P.L. and Linclau, L.A., Protection from Stress in Bone and Its Effects, The Journal of Bone and Joints Surgery, Vol.58-B, No.1 (1976), pp.107-113.

(11) Cordey, J., Perren, S.M. and Steinemannz, S.G., Stress Protection Due to Plates: Myth or Reality? A Parametric Analysis Made Using the Composite Beam Theory, Injury, Int. J. Care Injured, Vol.31 S-C (2003), pp.1-13.

(12) Chao, Y.S. and Hannu, T.A., Biomechanics of Fracture Fixation, Basic Orthopaedic Biomechanics, 2nd Edition, Edited by Van, M.C. and Hayes, W.C., (1997), pp.317-351, Raven Publishers.

(13) Laurence, M., Freeman, M.A.R. and Swanson, S.A.V., Engineering Considerations in the Internal Fixation of Fractures of the Tibial Shaft, Journal of Bone and Joint Surgery, Vol.51B, No.4 (1969), pp.754-768.

(14) Dennis, R.C. and Vasu, R., Stress Fields in the Unplated and Plated Canine Femur Calculated from in Vivo Strain Measurements, Journal of Biomechanics, Vol.14 (1981), pp.63-70.

(15) Gautier, E., Perren, S.M. and Cordey, J., Effect of Plate Position Relative to Bending Direction on the Rigidity of a Plate Osteosynthesis. A Theoretical Analysis, Injury, Int. J. Care Injured, Vol.31 S-C (2000), pp.14-20.

(16) Kesemenli, C., Subasi, M., Necmioglu, S. and Kapukaya, A., Treatment of Multifragmentary Fractures of the Femur by Indirect Reduction (Biological) and Plate Fixation, Injury, Int. J. Care Injured, Vol.33 (2002), pp.691-699.

(17) Tayton, K. and Bradley, J., How Stiff Should SemiRigid Fixation of the Human Tibia be? A Clue to the Answer, The Journal of Bone and Joint Surgery, Vol.65, No.3 (1993), pp.312-315.

(18) Chapman, J.R., Harrington, R.M., Lee, K.M., Anderson, P.A., Tencer, A.F. and Kowalski, D., Factors Affecting the Pullout Strength of Cancellous Bone Screws, Journal of Biomechanical Engineering, Vol.118 (1996), pp.391-398.

(19) Fan, L., Rondal, J. and Cescotto, S., Finite Element Modelling on Single Lap Screw Connection in Steel Sheeting under Static Shear, Thin-Walled Structures, Vol.27, No.2 (1997), pp.165-185.

(20) Lawrence, J.K., Mechanics of Hard Tissue, The Biomedical Engineering Handbook, Edited by Joseph, E. and Bronzino, D., (2000), CRC Press. 
(21) Ferguson, S.J., Wyss, U.P. and Pichora, D.R., Finite Element Stress Analysis of a Hybrid Fracture Fixation Plate, Medical Engineering Physics, Vol.18 (1996), pp.241-250.

(22) Ramakrishna, K., Sridhar, I., Sivashanker, S., Ganesh, V.K. and Ghista, D.N., Analysis of Internal Fixation of a Long Bone Fracture, Proceedings of 13th Interna- tional Conference on Mechanics in Medicine \& Biology, National Cheng Kung University, Taiwan.

(23) Ramakrishna, K., Development of Micro-Mechanics Models for Bone Fracture Fixation, Ph.D. Interim Report, Nanyang Technological University, Singapore, (2003). 